\title{
Diagnostic capabilities and treatment strategies depending on the form of non-alcoholic fatty liver disease in patients with hypertonic disease
}

\begin{abstract}
Objective: to provide data corroborating the relationship between non-alcoholic fatty liver disease (NAFLD) (in particular, non-alcoholic steatohepatitis (NASH)) and diseases of the cardiovascular system (in particular, hypertonic disease) and to study the prevalence of NAFLD in patients with hypertonic disease in Republic of Crimea and to compare the effectiveness of different strategies of treatment of NAFLD.

Materials and methods: The study included 100 patients with hypertonic disease stage II 2 degree. Dyslipidemia was registered in $65 \%$ of patients. All patients underwent ultrasound of the abdomen, biochemical blood analysis, blood tests for markers of viral hepatitis, and ${ }^{13} \mathrm{C}$-metathetin breath test. Frequency of NAFLD in the studied population was $55 \%$, in the group with hypercholesterolemia -45 persons $(69.2 \%)$. Among them, the patients were divided into 2 groups: $1 \mathrm{GR}(\mathrm{n}=22)$ with NASH received rosuvastatin $10 \mathrm{mg}$ at bedtime, essential phospholipids 2 caps. $\times 3 \mathrm{t} / \mathrm{d}$; Group $2(\mathrm{n}=23)$ without NASH received vitamin E $400 \mathrm{IU} 2 \mathrm{t} / \mathrm{d}$ for 1 month and rosuvastatin $20 \mathrm{mg}$ at night, for 6 months.

Results of the study: After 6 months of treatment comparable results were obtained in both groups: normal levels of transaminases and decreased total cholesterol and lipid profile parameters in $90.9 \%$ of patients $1 \mathrm{GR}$ vs. $91.3 \%$ of patients $2 \mathrm{GR}$, as well as improvement in the ${ }^{13} \mathrm{C}$-metathetin breath test that indicates the increase in mass of functioning hepatocytes.

Conclusion: Considering the high incidence of NAFLD in patients with cardiovascular disorders, especially in combination with hypercholesterolemia, it is useful in complex survey of patients include abdominal ultrasound, ${ }^{13} \mathrm{C}$-metathetin breath test, as well as determining of the level of transaminases, bilirubin, alkaline phosphatase and GGT. In the presence of NASH it is advisable to include essential phospholipids in therapy; in case of steatosis it is advisable to include vitamin $\mathrm{E}$ for 1 month which will reduce overall and cardiovascular mortality.
\end{abstract}

Keywords: non-alcoholic fatty liver disease, cardiovascular disease, ${ }^{13} \mathrm{C}$-metathetin breath test, essential phospholipids.
Volume 10 Issue 2 - 2019

\author{
Maksimova EV, Kliaritskaia IL \\ Medical Academy named after S.I. Georgievsky, Federal State \\ Autonomous Educational Institution of Higher Education \\ «Crimean Federal University named after V.I.Vernadsky», Russia

\begin{abstract}
Correspondence: Maksimova EV, Medical Academy named after S.I. Georgievsky, Federal State Autonomous Educational Institution of Higher Education «Crimean Federal University named after V.I.Vernadsky», Russia,

Email HelenMaksimovatt@mail.ru
\end{abstract}

Received: February 07, 2019 | Published: April 03, 2019

\section{Relevance of the topic}

Non-alcoholic fatty liver disease (NAFLD) is one of the most actual problems of modern medicine - is the subject of numerous studies, causing the interest of doctors of different specialties. According to the recommendations of the Russian Society for the Study of the Liver for the diagnosis and treatment of non-alcoholic fatty liver disease, non-alcoholic fatty liver disease includes steatosis, non-alcoholic steatohepatitis (NASH) and liver cirrhosis. ${ }^{1}$ According to EASL-EASD-EASO Clinical Practice Guidelines NAFLD is characterized by excessive hepatic fat accumulation, associated with insulin resistance (IR), and defined by the presence of steatosis in $>5$ $\%$ of hepatocytes according to histological analysis or by a proton density fat fraction $>5.6 \%$ assessed by proton magnetic resonance spectroscopy or quantitative fat/water selective magnetic resonance imaging. ${ }^{2}$

Non-alcoholic fatty liver disease is a liver damage in persons who do not abuse or drink alcohol. The degree of liver damage in NAFLD can vary from simple fat deposition without fibrosis or necrotic-inflammatory changes to the development of non-alcoholic steatohepatitis with varying degrees of fibrosis, necrosis and inflammation that further progresses to cirrhosis or hepatocellular carcinoma. ${ }^{1,2}$

According to the American Association for the Study of Liver Diseases, the morphological criterion of fatty hepatosis is triglycerides in the liver of more than 5-10\% of dry weight. ${ }^{3}$ According to epidemiological studies, NAFLD is the most common metabolic liver disease, which is primarily associated with an increase in the number of obese patients. The number of patients with NAFLD has recently increased significantly along with an increase in the prevalence of obesity and diabetes and is $20 \%$ in the general population. ${ }^{4}$

According to the EASL (2013), the prevalence of NAFLD in the general European population is 2-44\% (including children suffering from obesity) and $42.6-69.5 \%$ in people with type 2 diabetes. In the Russian Federation, the frequency of NAFLD was $27 \%$ in 2007 (according to an epidemiological study DIREG_L 01903, and 37.1\% - in 2014 (an increase of more than $10 \%$ ), which brings it to first place among liver diseases $-71.6 \%$ [4]. There is evidence that up to $80 \%$ of cases of cryptogenic cirrhosis are the outcome of NAFLD, and it is NAFLD that ranks third among the indications for liver transplantation in the United States of America. ${ }^{5}$ 
According to modern concepts, NAFLD is positioned as an independent risk factor for the development and progression of cardiovascular diseases (CVD) (Misra V.L. et al., 2009). The most important factor in this risk is atherogenic dyslipidemia, which is detected in $20-80 \%$ of patients with NAFLD. A number of studies have shown the association of NAFLD with arterial hypertension (AH). It is also established that CVDs are the main cause of death for patients with NAFLD (Musso G. et al., 2012; Farrell G.C. et al., 2013). About 9.4 million people in the world die from CVD every year, among them $51 \%$ due to stroke (outcome of hypertension and cerebrovascular disease) and $45 \%$ due to coronary heart disease. ${ }^{6,7}$

Arterial hypertension is a common disease that affects up to 40 $\%$ of the Russian population. ${ }^{3}$ At the same time, the frequency of diagnosing concomitant hypertension with non-alcoholic fatty liver disease has significantly increased to $23-58 \%$, and in patients with overweight this pathology is observed in 74-100\%. In patients with hypertension and NAFLD, unstable hypertension with episodes of hypotension and lack of effectiveness of antihypertensive therapy are often observed. As a result, the presence of NAFLD in a patient with hypertension, as is known, increases the risk of mortality from cardiovascular complications. ${ }^{10,11}$ The most common risk factors for NAFLD in the population are: dyslipidemia, abdominal obesity, arterial hypertension. For each risk factor, the proportion of patients in the NAFLD population was higher than the proportion of patients with the same risk factor in the entire population of patients included in the analysis. ${ }^{7,12,13}$

NAFLD is a risk factor for the development of the cardiovascular system diseases and determines the outcome of diseases of the cardiovascular system to a greater extent than the outcome of liver diseases. This circumstance has been confirmed in a number of population studies. ${ }^{14}$ In patients with NAFLD, there is a higher overall and cardiovascular mortality, especially at the age of $45-54$ years. ${ }^{15}$

In a study by Toledo et al. (2006) showed that plasma insulin was higher in patients with steatosis than in control group patients. At the same time, the level of insulin correlated much less with the level of triglycerides in comparison with the correlation between the level of triglycerides and the severity of steatosis. These data indicate the possible presence of a direct pathogenetic chain between liver steatosis and dyslipidemia, and further - atherosclerosis. A number of studies have confirmed the relationship between the thickness of the intima media of the carotid artery and the degree of histological changes in the liver. In addition, when NAFLD increases the risk of thrombosis by increasing the pool of proinflammatory cytokines, proatherogenic dyslipidemia, hypercoagulation and hypofibrinolysis. ${ }^{16-19}$

NAFLD can act as the only manifestation of lipid metabolism disorders, and as a component of the metabolic syndrome (MS). The presence of NAFLD in MS is due to a single pathogenesis, in which the main roles are played by visceral (abdominal) obesity and insulin resistance (IR). The data obtained that the risk of NASH in patients with MS depends on the degree of IR. According to the results of the correlation analysis, statistically significant direct correlations were found between the degree of IR, the level of insulin, C-peptide and diagnostic markers of NASH (AsAT and AlAT); $(r=0.26-0.42 ; \mathrm{p}$ $<0.05){ }^{20}$

In patients with type 2 diabetes mellitus (DM), fat accumulation in the liver, whose content was measured by proton magnetic resonance spectroscopy, was most associated with insulin-stimulated glucose uptake by myocardiocytes compared with other indicators, such as mass of visceral fat tissue or total glucose uptake in the body. ${ }^{21}$
There is no doubt that the fatty infiltration of the liver is associated with insulin resistance, atherosclerosis and metabolic syndrome. Liver steatosis is a predictor of cardiovascular events and is considered as the 6th criterion of the metabolic syndrome. It should be noted that insulin resistance - the main factor in the development of NAFLD - is an independent risk factor for CVD and DM type 2. The clinical significance of metabolic disorders and diseases, united within the framework of IR syndrome, is great, and their combination greatly accelerates the development and progression of atherosclerosis and associated CVD. ${ }^{22}$

Recent studies have shown that almost all components of MS are risk factors leading to the formation of liver fibrosis. Clinical predictors of liver fibrosis and cirrhosis in NAFLD were identified: type 2 diabetes, arterial hypertension, body mass index $(\mathrm{BMI})>32.3$ $\mathrm{kg} / \mathrm{m}^{2}$ (women); BMI $>31.1 \mathrm{~kg} / \mathrm{m}^{2}$ (men), increased C-peptide, age $>$ 45 years, Increased triglycerides (TG) $>1.7 \mathrm{mmol} / 1$, ALT $>2$ upper limits of normal, AST / ALT $>1 .{ }^{23}$ The relationship of NAFLD with risk factors of diabetes mellitus type 2 and cardiovascular disease continues to be debated. Despite the increasing prevalence of NAFLD among patients with obesity, the pathogenetic mechanisms underlying it are not well understood. All this indicates the relevance of the study of the problem.

Despite the high interest in NAFLD in world medical science, in domestic practice in relation to a particular patient, this problem is often overlooked. This is due to the fact that most often steatosis is detected by chance during an outpatient examination, and during that relatively short period of time, while the doctor observes the patient, the liver disease does not progress. It is necessary to consider a patient with NAFLD taking into account comorbidity and not only from the point of view of a separate specialty. Clear approaches to the treatment of NAFLD are not defined. To date, there are no clear algorithms for managing patients even with NAFLD, and even more so, when combining NAFLD with cardiovascular diseases, respectively, priorities in the choice of drugs, taking into account inter-drug interactions and duration of therapy, are not determined. The generally accepted approaches to the diagnosis of NAFLD and comorbid pathology have not been developed. Methods for monitoring the effectiveness of treatment and criteria for determining the prognosis of NAFLD and comorbid pathology are also insufficiently studied.

Objective: to study the prevalence of NAFLD in patients with cardiovascular diseases and to compare the effectiveness of various treatment strategies for NAFLD.

\section{Materials and methods}

The study included 100 patients with stage II hypertensive disease, aged between 45 and 60 years. Before inclusion in the study all patients signed an informed consent. All patients underwent an ultrasound examination of abdominal organs, biochemical blood tests (determination of ALT, AST, gamma GT (GGT), bilirubin, alkaline phosphatase, total cholesterol $(\mathrm{CH})$, triglyceride (TR) levels, low-density lipoproteins (LDL), high-density lipoproteins (HDL)), determination of the HOMA index (insulin resistance index), blood test for viral hepatitis markers (to rule out viral etiology of liver damage), 13C-methacetin breath test (13C-MDT).

${ }^{13} \mathrm{C}$-metathetin breath test (13C-MBT) was used to determine the mass of functioning hepatocytes..$^{15}$ The principle of the method is that the non-radioactive labeled ${ }^{13} \mathrm{C}$ - metathetin (a derivative of phenacetin) is exposed to enzymatic demethylation and decarboxylation with microsomal cytochrome $\mathrm{P}_{450}$ in the liver. The 
end product of metabolism of ${ }^{13} \mathrm{C}$ - metathetin is ${ }^{13} \mathrm{CO}_{2}$, the intensity of selection of which through the lungs gives possibility to indicate the functional status of the microsomal enzyme systems of hepatocytes. During the test 10 respiratory samples were received: initial - before taking the test breakfast $\left(75 \mathrm{mg}{ }^{13} \mathrm{C}\right.$ - metathetin dissolved in $200 \mathrm{ml}$ of tea without sugar), 6 more samples during the first hour (one sample every 10 minutes) and three - during the second hour (one sample every 20 minutes). Analysis of samples was performed on an infrared spectrometer IRIS (Germany). Table 1 shows the performance of normal and pathological ${ }^{13} \mathrm{CO}_{2}$ total concentration and its relation to hepatic functional mass (HFM). The sensitivity and specificity is over $90 \% .^{\mathrm{s}}$

Table I Evaluation of ${ }^{13} \mathrm{C}$ - metathetin breath test results

\begin{tabular}{ll}
\hline $\begin{array}{l}\text { The total concentration of }{ }^{13} \mathbf{C O}_{2} \\
\text { to the } \mathbf{I} \mathbf{2 0}^{\text {th }} \text { minute,\% }\end{array}$ & Interpretation of results \\
\hline$>35 \%$ & Stimulated liver function \\
$20-35 \%$ & Normal liver function, HFM I00\% \\
$10-20 \%$ & Moderate decrease of liver detoxification function without cirrhotic changes, HFM $50-100 \%$ \\
$2-10 \%$ & Marked reduction of liver detoxification function with cirrhotic changes, HFM $20-50 \%$ \\
$<2 \%$ & Severe reduced function of the liver with cirrhotic changes, MFG $<20 \%$ \\
\hline
\end{tabular}

The incidence of NAFLD in the studied population was $55 \%$, in the group with hypercholesterolemia -45 people $(69.2 \%)$, among them the patients were divided into 2 groups: the 1st group $(n=22)$ with nonalcoholic steatohepatitis (NASH) received rosuvastatin in a dose of $20 \mathrm{mg}$ at night, essential phospholipids in 2 capsules $\times 3 \mathrm{t} / \mathrm{d}$; group $2(\mathrm{n}=23)$ without NASH received vitamin E $400 \mathrm{IU} \times 2 \mathrm{t} / \mathrm{d}$ for 1 month and rosuvastatin in a dose of $20 \mathrm{mg}$ at night, throughout 6 months.

Table 2 Data of lipid profile in groups before treatment

\begin{tabular}{|c|c|c|c|c|}
\hline & $\mathrm{CH}(\mathrm{mmol} / \mathrm{l})$ & TR ( $\mathrm{mmol} / \mathrm{l})$ & LDL (mmol/l) & HDL (mmol/l) \\
\hline Group I & $6,75 \pm 1,86$ & $3,68 \pm 1,02$ & $4,26 \pm 1,78$ & $|| 15 \pm 0,,2 \mid$ \\
\hline Group 2 & $6,21 \pm 1,43$ & $3,17 \pm 0,97$ & $3,89 \pm 1,32$ & $1,35 \pm 0,44$ \\
\hline
\end{tabular}

According to the results of ${ }^{13} \mathrm{C}$ - metathetin breath test (Table 3), moderate decrease of hepatic functional mass (HFM) was observed in most patients in both groups $(77.3 \%$ in group 1 and $65.2 \%$ in group 2).

Evaluation of treatment effectiveness was carried out after 6

months of treatment. After 6 months of treatment, comparable results were obtained in both study groups: normal transaminase parameters and a decrease in total cholesterol and parameters of lipid profile in $90.9 \%$ of patients of the 1 st group versus $91.3 \%$ of patients of the 2 nd group, as well as improvement of $13 \mathrm{C}$ parameters-MDT, indicating an increase in the mass of functioning hepatocytes (Table 4).

Table 3 Results of ${ }^{13} \mathrm{C}$ - metathetin breath test in groups before treatment

\begin{tabular}{|c|c|c|c|c|c|c|}
\hline & \multicolumn{2}{|c|}{ Normal liver function } & \multicolumn{2}{|c|}{$\begin{array}{l}\text { Moderate decrease of liver } \\
\text { detoxification function }\end{array}$} & \multicolumn{2}{|c|}{$\begin{array}{l}\text { Marked reduction of liver } \\
\text { detoxification function }\end{array}$} \\
\hline & $\mathbf{n}$ & $\%$ & $\mathbf{n}$ & $\%$ & $\mathbf{n}$ & $\%$ \\
\hline $\begin{array}{l}\text { Group I } \\
(n=22)\end{array}$ & 3 & 13,6 & 17 & 77,3 & 2 & 0,1 \\
\hline $\begin{array}{l}\text { Group } 2 \\
(n=23)\end{array}$ & 7 & 30,4 & 15 & 65,2 & I & 0,04 \\
\hline
\end{tabular}

Table 4 Results of ${ }^{13} \mathrm{C}$ - metathetin breath test in groups after treatment

\begin{tabular}{|c|c|c|c|c|c|c|}
\hline & \multicolumn{2}{|c|}{ Normal liver function } & \multicolumn{2}{|c|}{$\begin{array}{l}\text { Moderate decrease of liver } \\
\text { detoxification function }\end{array}$} & \multicolumn{2}{|c|}{$\begin{array}{l}\text { Marked reduction of liver } \\
\text { detoxification function }\end{array}$} \\
\hline & $n$ & $\%$ & $\mathbf{n}$ & $\%$ & $n$ & $\%$ \\
\hline $\begin{array}{l}\text { Group I } \\
(n=22)\end{array}$ & 17 & 77,3 & 5 & 22,7 & 0 & 0 \\
\hline $\begin{array}{l}\text { Group } 2 \\
(n=23)\end{array}$ & 21 & 91,3 & 2 & 8,7 & 0 & 0 \\
\hline
\end{tabular}

Citation: Maksimova EV, Kliaritskaia IL. Diagnostic capabilities and treatment strategies depending on the form of non-alcoholic fatty liver disease in patients with hypertonic disease. Gastroenterol Hepatol Open Access. 20 19; I0(2): I I 2-I I 5. DOI: I0.15406/ghoa.20 I 9. 10.00367 


\section{Conclusion}

Considering the high incidence of NAFLD in patients with cardiovascular disorders, especially in combination with hypercholesterolemia, it is useful in complex survey of patients include abdominal ultrasound, 13C-metathetin breath test, as well as determining of the level of transaminases, bilirubin, alkaline phosphatase and GGT. In the presence of NASH it is advisable to include essential phospholipids in therapy; in case of steatosis it is advisable to include vitamin $\mathrm{E}$ for 1 month which will reduce cardiacrelated mortality.

\section{Acknowledgments}

None.

\section{Conflicts of interest}

Authors declare no conflicts of interest.

\section{References}

1. Ivashkin VT, MV Mayevskaya, Ch S Pavlov. Clinical guidelines for the diagnosis and treatment of non-alcoholic fatty liver disease of the Russian Society for the Study of the Liver and the Russian Gastroenterological Association. RZGGK. 2016;2:24-42.

2. European Association for the Study of the Liver (EASL). EASL-EASDEASO Clinical Practice Guidelines for the management of non-alcoholic fatty liver disease. J Hepatol. 2016;64(6):1388-1402.

3. Noureddin, Yates KP, Vaughn IA. Clinical and histological determinants of nonalcoholic steatohepatitis and advanced fibrosis in elderly patients. Hepatology. 2013;58(5):1644-1654.

4. Masarone M, Frederico, Abenavoli L, et al. Non Alcoholic Fatty Liver. Epidemiology and Natural history. Rev Recetn Clin Trials. 2014;9(3):126-133.

5. Drapkina OM, Ivashkin VT. Epidemiological features of non-alcoholic fatty liver disease in Russia (results of an open, multicenter, prospective study of observation DIREGL 01903). Russian Journal of Gastroenterol hepatol coloproctol. 2014;24(4):32-38.

6. Klyaritskaya IL, Maksimova EV, Shahbazidi G, et al. Non-alcoholic fatty liver disease and its rare forms. Crimean Therapeutic Journal. 2017;1:41-46.

7. Palgova LK. Genetic factors of the pathogenesis of NAFLD: fundamental and applied aspects. Are there any solutions? Consilium medicum. Gastroenterology. 2014;1:18-23.

8. Klyaritskaya IL, Maksimova EV, Tsapyak TA. Modern view on the problem of non-alcoholic fatty liver disease. Crimean therapeutic journal. 2006;1:49-54.
9. Masuoka HC, Chalasani N. Who should be screened for NASH? Ann N Y Acad Sci. 2013;1281:106-122.

10. Pavlov Ch S, Glushenkov DV, Ivashkin VT. Diagnostics of nonalcoholic fatty liver disease using non-invasive screening methods of the population. Vrach. 2010;12:13-19.

11. Ivashkin VT, Drapkina OM, Shulpekova Yu. O. Diagnostics and treatment of non-alcoholic fatty liver disease (methodical recommendations). Moscow: M-Vesti Publishing House. 2009. 20 p.

12. Komova AG, Mayevskaya MV, Ivashkin VT. Principles of effective diagnosis of diffuse liver diseases in the outpatient stage. Ros Journal gastroenterol hepatol coloproctol. 2014;24(5):36-41.

13. Martínez SM, Crespo G, Navasa M, et al. Noninvasive assessment of liver fibrosis. Hepatology. 2011;53(1):325-335.

14. Wiernsperger N. Treatment Strategies For Fatty Liver Diseases. Rev Recent Clin Trials. 2014;9(3):185-194.

15. Nikitin IG Screening program to identify the prevalence of non-alcoholic fatty liver disease and determine the risk factors for the development of the disease. Grew up honey. 2010;1(XV):41-46.

16. Dunn W, Xu R, Wingard DL, et al. Suspected nonalcoholic fatty liver disease and mortality risk in a population-based cohort study. Am J Gastroenterol. 2008;103(9):2263-2271.

17. Eliseeva LN, Blednova AYu, Samorodskaya NA, et al. Non-alcoholic fatty liver disease and markers of cardiovascular pathology. Ros honey. 2010; $1(\mathrm{XV}): 47-53$.

18. Bellentani S, Dalle GR, Suppini A, et al. Behavior therapy for nonalcoholic fatty liver disease: the need for a multidisciplinary approach. Hepatology. 2008;47(2):746-754.

19. Tkachenko EI, Uspensky Yu P, Belousova LN, et al. Non-alcoholic fatty liver disease and metabolic syndrome: unity of pathogenetic mechanisms and treatment approaches. Experimental and wedge Gastroenterology. 2008;2:92-96.

20. Abdelmalek M.F., Diehl A.M. Nonalcoholic fatty liver disease as a complication of insulin resistance. Med Clin North Am. 2007;91(6):11251149.

21. Aller R, de Luis DA, Fernandez L, et al. Influence of insulin resistance and adipokines in the grade of steatosis of nonalcoholic fatty liver disease. Dig Dis Sci. 2008;53(4):1088-1092.

22. Angelico F, Del Ben M, Conti R, et al. Insulin resistance, the metabolic syndrome, and nonalcoholic fatty liver disease. J Clin Endocrinol Metab. 2005;90(3):1578-1582.

23. Bugianesi E, Gastaldelli A, Vanni E, et al. Insulin resistance in nondiabetic patients with non-alcoholic fatty liver disease: sites and mechanisms. Diabetologia. 2005;48(4):634-642. 